\title{
Effect of Conjugated Estrogen in Stress Urinary Incontinence in Women with Menopause
}

\author{
Somayeh Khanjani ${ }^{*}$, Sareh Khanjani \\ ${ }^{1}$ Obstetrics and Gynecology, Isfahan, Iran \\ ${ }^{2}$ School of Medicine, Shahr e Kord University of Medicine Science, Shahr e Kord, Iran \\ Email: ^somayeh.khanjani@yahoo.com,sareh.khanjani@yahoo.com
}

How to cite this paper: Khanjani, S. and Khanjani, S. (2017) Effect of Conjugated Estrogen in Stress Urinary Incontinence in Women with Menopause. International Journal of Clinical Medicine, 8, 375-385.

https://doi.org/10.4236/ijcm.2017.86035

Received: April 13, 2017

Accepted: June 20, 2017

Published: June 23, 2017

Copyright (c) 2017 by authors and Scientific Research Publishing Inc. This work is licensed under the Creative Commons Attribution International License (CC BY 4.0).

http://creativecommons.org/licenses/by/4.0/

\begin{abstract}
Menopause is one of the natural stages of life of women that is associated with instability of vasomotor, flushing, sweating, anxiety and depression, urogenital atrophy and urinary problems. The age range of physiological event is between 48 - 55 years old. With regard to the role of genetics, nutrition and geographical conditions of the age of menopause in Iranian women is lower than and among 46 - 53 years. With the increase in life expectancy in recent decades, duration of menopause is increased and almost involved a third of the life of women so special issues of this era have had more attention. Since menopause is not the end of the life of a woman and keep her physical and mental health and problems resulting from the process of menopause such as urinary problems and incontinence will lead to improve the quality of life in this period. Many studies have tried to find a therapy for postmenopausal women with stress urinary incontinence using hormone. So this article seeks to examine the effect of conjugated estrogen in stress urinary incontinence of menopausal women with using the library method. The survey showed that by starting menopause, decreasing estrogen causes atrophy of mucosa of urogenital and the lining of the urethra and bladder, estrogen causes to maintain muscle tonicity. Also sacral nerves are also rich in estrogen receptors and by estrogen deficiency, elasticity of the urinary system decreases. Estrogen deficiency causes excitability of nerves and frequency of urine. So estrogen can increase the resistance of the urethra, bladder sensory threshold and sensitivity in Adorno in smooth muscles of the urethra and the rest of detrusor.
\end{abstract}

\section{Keywords}

Menopause, Stress Urinary Incontinence, Steroid Hormones, Vaginal Atrophy, Bladder Prolapse, Conjugated Estrogen

\section{Introduction}

Urinary incontinence is common diseases of women in childbearing ages that by 
increasing age, its incidence will be more [1]; the patients involved 15 to 50 percent of women in society that type of stress is more common [2]. Women because of the anatomy, social and cultural are more prone to this disease [3]. Urinary incontinence is the involuntary loss of urine which is objectively demonstrable and is a social and health problem [4]. The urinary incontinence that occurs in various forms, including the severe form of daily attacks a lot, an average of 1 to several times a week in the perspiration, the slight i.e. drop oozing weekly or monthly. Stress Urinary Incontinence is a common problem that in women its prevalence is $10 \%$ to $58.4 \%$ and most recently, with increasing survival, its incidence has increased [5].

Urinary incontinence is a major problem in menopause that affects almost $56 \%$ of menopausal women [6]. Menopause is one of the critical stages of women's lives and is inevitable [7]. This step is the mark of the transition from fertility to infertility [8]. Menopause is the most important event of middle-aged women that in terms of personal, cultural and social; it is important as a health problem in the whole reproductive health and women have a particular significance [9]. Now menopause happens between the ages of 40 - 60 years and an average of 51 years [10] and by increasing the lifespan, women spend about a third of their life for postmenopausal. Onset of menopause is gradual and usually begins with changes in the menstrual cycle; these changes begin at the end of the third decade of life [11]. Postmenopausal women involved with endocrine changes, physical and psychological, which have arisen due to prolonged deprivation of estrogen and cause considerable distress and disability in women [12].

The health problems caused during menopause have been considered. One of the physical changes during this period is urogenital changes, genital-urinary atrophy that leads to various symptoms and impact on the comfort and quality of life.

Vagina, external genitalia, urethra and bladder trigone have embryonic close together and all have large numbers of receptors of estrogen. The aging of the genitourinary system by high levels of circulating estrogen is adjusted. Urinary incontinence in women causing great financial pressure for them so that direct cost of which is estimated 10.5 million dollars per year. In addition to the Financial Times, these people are mentally loss of self-confidence, a sense of shame and a tendency to isolation and are suffering from bed sores [13].

Studies show that urinary incontinence has a strong influence on physical activities, social, emotional and mental of patients, especially women. This disease is considered a shameful position in person's mind which leads to drop out of society, loss of sense of self-efficiency and hence the drop in quality of life [14]. Quality of life of each person is considered a main indicator and involved various aspects like physiologic aspects, mental performance, so pay attention to it has a particular importance [15]. There is a reciprocal relationship between the disease and quality of life, so that the primary goal of treatment is to improve the quality of life by reducing the effects of disease on the lives of individuals [16]. 
Women constitute half of the population and women's health affects the health of future generations, so the question of quality of life for women, because of their position in family is important Jaygashan [17]. On the one hand, intervention for incontinence with physical, mental and social effects to improve quality of life requires comprehensive theories [18].

The role of estrogen and progesterone and $\mathrm{p} 53$, in creating prolapse of pelvic organ and stress urine incontinence is reported in numerous research studies [19]. That based on the subject of this article, a number is mentioned. Results of various studies show that vaginal atrophy, uterine prolapse, cystocele, Rectocele, Ectropion, cervix ulcer and irritation in women increases. Traumatic vaginal bleeding was observed in $15 \%$ of cases. The urethral syndrome, nocturnal enuresis, urinary tract infection is reported in $7 \%-10 \%$ of postmenopausal women [20]. In the study by Bai et al. that P53 level and estrogen receptor, progesterone in perry urethral fascia of postmenopausal women with stress urinary incontinence and normal women was investigated, the incidence of P53 and estrogen receptor in stress urinary incontinence significantly was lower than the control group [21]. In a study by Zhu and his colleagues, the level of estrogen receptor in tissues of Pelvic floor of patients with stress incontinence was reported significantly lower than the control group [22]. [23] is titled the relationship between menopause and urinary incontinence that women with urinary incontinence than those who did not have, significantly had higher BMI [24]. In a large study of postmenopausal women with symptoms of urinary incontinence (URG or $\mathrm{SU}$ ) with Estrogen treatment, a big improvement was observed in the number of incontinence, frequency and increasing bladder capacity and increasing the capacity of the first sensation to urinate [25]. In one study, use of vaginal cream in 1.3 outer of the vagina increase blood flow to the urinary but in depth of vagina with effect on the uterus, urinary incontinence has increased i.e. the location of estrogen in frequency of incontinence has been effective [26].

Today, due to increasing life expectancy and life expectancy in women and reduce the average age of menopause, understanding the problems of women in this age is very important. Therefore, this article seeks to examine the effect of conjugated estrogen in stress urinary incontinence of menopausal women.

\section{The Definition of Concepts}

1) Definition of menopause: according to the definition of World Health Organization, menopause means the cessation of menstruation for at least 12 months due to the loss of activity of ovarian follicles [27]. In terms of laboratory, cessation of menstruation, along with a decrease in estrogen and an increase in FSH (follicle stimulating growth hormone) to more than $40 \mathrm{~mm}$ units per liter represents menopause [28]. Now menopause between the ages of $40-60$ years and average 51 years happens [29].

2) Stress urinary incontinence: the involuntary excretion of urine when coughing, sneezing, running, and jumping or any activity leading to increase pressure inside the abdomen [30]. 


\subsection{Menopause and Steroid Hormones}

Estrogen is female sex hormones which consist of three main types, Beta estradiol, estrone and estriol and is a major factor in the incidence of secondary sexual characteristics [31]. Menopause is associated with hormonal changes, clinical and biological. With the onset of the menopause, the ovaries stop producing considerable quantities of estrogen; hence the symptoms and problems associated with estrogen deficiency occur gradually. Among the changes is atrophy of urinary-genital tract that followed by it problems such as urinary urgency, urinary frequency, nocturia, urinary stress incontinence, urge incontinence, vaginal atrophy and dyspareunia occurs [32]. Studies have attributed the physiological cause of this association to estrogen receptors in genitourinary system. The existence of the first estrogen receptor alpha in the urinary-genital tract proved in 1958 [33]. Then in 1996, the second beta estrogen receptor was identified [34]. These receptors exist in cells of squamous epithelium of the initial and final part of the urethra, bladder triangle, urinary sphincter, the walls of the vagina, pelvic floor muscles and pelvic diaphragm and thus the role of estrogen in the performance of the device and also lack of this hormone in disorders of the urinary-genital tract is undeniable [35]. In addition to estrogen, other receptors in other tissues of the urinary-genital tract have been identified that have specific performance for hormones such as androgen and progesterone. It should be noted that the role of these receptors is less than estrogen receptors, but these receptors in the bladder triangle, the overall context of the bladder, urethra and the vaginal walls has been proved. New studies indicate the role of progesterone in the genitourinary system, but the functional role of androgens in this device is still not clearly determined.

Steroid hormones in addition to environmental effects in the urinary tract have a central role in the neural control of urination process. However, the exact mechanism of this action is unknown, but the presence of both types of estrogen receptors in the brain cortex, limbic system, the hippocampus and the cerebellum has been proved [36]. Due to the position and function of steroids in the urinary tract, the use of replaced hormone therapy in menopause has long attracted the attention of researchers and providers of health care in this area.

\subsection{Natural Changes of Genitourinary Tract in Menopausal}

Content of external genitalia, including vagina-urethra and bladder trigone have embryonic close together, and all have estrogen receptor unit. The aging of the urinary system is determined by the amount of circulating estrogen. Tissues of urogenital do not find atrophy with one speed. Atrophy in the period before menopause is started and will continue for many years. The external genitalia, although not derived from Mullerian structures but with estrogen deprivation quickly is with atrophy. By increasing age, hair becomes thinner in pubis, labia will be shrink and by the reduction of subcutaneous fat and elasticity, the great lip is wider and so vaginal epithelium becomes thinner and less resistance more and more pale and superficial cells replace intermediate cells also, vaginal dis- 
charge and vaginal acid also subsequently reduced and pathogens can easily grow in it. Change in vaginal PH from 3.5 - 4 to 6 - 8 lead in alkaline of environment which results in colonizing a large number of bacteria prone. Vaginal or systemic administration of estrogen reverses the trend of thinning of the vaginal mucosa and reduce its PH. Treatment should continue for 1 - 3 months and to remain in effect, only its interrupted use is enough [37].

Urethral area is affected by lack of estrogen. The lower portion of the urethra may be hard and inelastic that this case predisposes diverticulum and Ureterocele. Urethral syndrome is the most common problem in postmenopausal women associated with changes in the urethra. This syndrome includes burning and frequent urination, difficulty in urination, nocturia and urinary urgency. When these symptoms are associated with negative urine culture, diagnosis of urethral syndrome arises. This condition is treatable with therapy of estrogen or wide the urethra. Bacteriuria is seen in $7-10$ percent of menopausal women while this rate before menopause is 4 percent, higher incidence in postmenopausal women may be due to vaginal atrophy and increasing pollution through the vaginal by the natural disability the external urethral perforation into the anterior vaginal canal, estrogen therapy often leads to healing. The natural shorten of urethra that with postmenopausal atrophic changes will lead to incontinence should be considered [38].

Estrogen deficiency results in decreasing muscle tonicity in the pelvic floor and following the reduction of the circulation of blood of genitourinary muscle area causes to reduce muscle strength and so drooping of muscles. By doing Kegel Exercises, strength in the muscles of genitourinary increases thus recommended that the diet containing soy products, sunflower oil and nuts, which contain high levels of estrogen and are useful in improving muscle work to be used.

Also stop the flow of urine in midstream urine causes to strengthen the pelvic floor muscles. The most common symptoms and complaints in postmenopausal women is external genital itching. Usually replacement therapy with hormone or estrogen in removing itching is quite effective. However dystrophy of genital can cause itching. Differentiation of dystrophy from simple atrophy is important because 5 percent of dystrophies of external genitalia after 3 - 5 years become squamous cell carcinoma [39].

It does not seem that the first cause of dystrophy or carcinoma of external genitalia is estrogen deprivation. Estrogen deficiency causes ease of vulnerability of vaginal. Hit to vaginal may be responsible for about 15 percent of bleeding after menopause, and on the other hand, the incidence of Vaginitis over the years after menopause increases.

Three types of lesion of erosion, ectropion and cervical lesions in post-menopause is seen more. Endocervix glandular tissue activity during menopause and subsequently the amount of mucin decreases that this causes to vaginal dryness that arises as a main complaint in postmenopausal women. The junction of cylindrical cobblestone coverage and columnar and transformation zone 
moves a lot to the endocervical canal that creates problems in Pap test and colposcopy.

The incidence of uterine prolapse, cystocele and Rectocele increases in menopause that only limited evidence consider the cause from estrogen deprivation. This increase probably is due to lack of estrogen with age-related decline in cell division and reducing elasticity of tissues of area [40].

\subsection{Bladder Prolapse and Urinary Stress Incontinence}

The bladder is a sac like organ that is inside the pelvis and its duty is to hold urine that from kidneys and through ureter pipe is leaking into it. The hollow member by supporting muscles is placed in a right place and if for any reason the supporting muscles lose the ability, bladder displaced from its place and creates problems for the individual. The name of this disease is prolapse of bladder [41].

The first symptom of the disease is feeling of pressure that the individual feels in vaginal area and when touch it, it is like a round and small ball. Another very common signs is urinary incontinence that person with a sneeze, cough or laugh suddenly excreted urine. Prolapse of bladder disease is specific for ladies. Normally anterior vaginal wall in women protects the bladder in its place. When the wall is placed under pressure, muscles stretch and relaxes their supportive role of the bladder is destroyed. One of the cases that are in expose of this disorder is post-menopausal women. Common causes of bladder irritability during menopause include:

1) Weakening of the pelvic floor muscles: pelvic floor muscles during menopause naturally become weaker and may the control of bladder be less and may lead to that person to go to the bathroom constantly.

2) Prolapse: prolapse is prolapse of organs (such as Uterus, vagina and bladder) in the pelvic floor. Some women who have prolapse feel that have a mass in their vagina that can result from prolapse of Uterus, bladder or bowel into it and damage or strain to pelvic floor muscles.

3) Reduce elasticity and stretching of the bladder: bladder may lose its ability to stretch and in this case cannot have elongation and increasing the volume and hold more urine. As a result it is triggered as soon as the filling. It is leading to overactive of bladder and causes an urgent need to go to the bathroom and urinate constantly.

4) Estrogen reduction: with the beginning of menopause, estrogen level becomes lower. Reduce estrogen level is leading to severe urinary incontinence. Because the hormone estrogen in the body cause to muscles have strength in well. By cutting off estrogen, muscles all over the body, including the anterior vaginal relaxed and bladder prolapse is seen in postmenopausal women.

5) Overweight: many women during menopause because of changes that occur in their body are overweight. As a result, by increasing weight, pelvic floor muscles and bladder will be strained and leading to stress incontinence (stress incontinence) in them [42]. 


\subsection{Diagnostic Measures of Stress Urinary Incontinence}

By describing after suspect to stress incontinence, it can be proved its measures. Important diagnostic measures include:

1) Urodynamic test where pressures of bladder and urethra are measured.

2) Cystoscopy: The most important diagnostic test in which maneuvers of abdominal pressure and urine leakage can be seen [43].

\subsection{Conjugated Estrogen}

Estrogen in healthy women causes growth and development of sex organs and maintaining the normal function of genitourinary and increase stability of blood vessels (as a result avoid cramp). Hormone therapy (estrogen) in postmenopausal women alleviates urinary frequency and dysuria and blood flow of bladder tissue increases and leads to increase the strength of muscles around the urethra [44].

When estrogen is used as replacement therapy in postmenopausal women with natural menopause or after surgery become menopausal, the treatment prevents estrogen deficiency symptoms, such as hot flashes and vaginal dryness, osteoporosis and atherosclerosis (hardening of the wall of the arteries or atherosclerosis) [45].

Conjugated estrogen for women in continuously (every day) or period (in 21 to 25 days per calendar month) is indicated. Edible form drug can be taken with vaginal forms [46].

Warnings and side effects of conjugated estrogens has been long-term without use of progestin with the risk of endometrial cancer. In addition, women who are taking estrogen, if vaginal bleeding should refer doctor immediately. Patients using estrogen should report symptoms like, pain in the chest, groin, or legs, sudden and severe headache, sudden shortness of breath, slurred speech, sudden changes in vision, or weakness in hands and feet immediately to doctor. Also symptoms like, cramps, bloating, nausea, mild dizziness, mild diarrhea, change in sexual desire, or the inability to tolerate contact lenses may be created if causes problem they should be discussed with doctor [47].

In the case of catching thrombophlebitis, thrombosis (blood clots in the veins), or thromboembolic disorders, endometriosis, gallbladder diseases, uterine fibroids, breast cancer or suspected (except on those who use due to estrogen), abnormal and undiagnosed vaginal bleeding, or liver problems, patients should be caution in using estrogen drug [47].

\section{Conclusions}

Menopause is one of the natural phases of a woman's life that associated with changes in the ovaries and the hormones secreted from it. These changes occur before stopping menstrual cycle. Sometimes the changes are long and show themselves as increasing or decreasing hormone level. The time range of the change is between 1 - 10 years. The average age of natural menopause is 51 years old. Menopause sometimes occurs following the removal of both ovaries after 
surgery, radiotherapy, chemotherapy, endocrine disorders or malnutrition. Menopause can be affected on different organs including the cardiovascular systems, nervous, urinary and reproductive that the genitourinary tract changes were discussed in this article.

Menopause is usually associated with urinary incontinence. Menopause is a period that creates changes in the lives of women. Urinary incontinence is common in postmenopausal women which can also affect their social life. When due to the menopause, estrogen level decreases, urogenital system, including urinary mucus layer begins to atrophy and reduce urethral mucosal vascular network and urinary muscle sensitivity to alpha-adrenergic stimulation decreases which causes urinary incontinence. The anterior vaginal wall in maintenance of urine by supporting the urethra and bladder when increasing abdominal pressure helps and ligament sacral prevents the uterus and vagina prolapse by fixing the upper part of vagina and cervix and uterus to the pelvic diaphragm. The effect of estrogen and progesterone on the connective tissue is connective to the reproductive system through receptors in the tissues. Estrogen is influenced through two types of estrogen receptor of alpha and beta and possibly due to reduce the level of these receptors and genetic background, connective tissue disorders occur.

Many studies have tried to find a therapy for postmenopausal women with stress urinary incontinence using hormone and in some studies the effect of hormone therapy (conjugated estrogens) in the treatment of these disorders has been reported. Hormone therapy (estrogen) in postmenopausal women alleviates urinary frequency which leads to increase in the strength of muscles around the bladder.

\section{References}

[1] Denfort, D. (2002) Obstetrics and Gynecology. Sarami, A., et al., Trans., Miri Press, Tehran.

[2] Novak, E. (2003) Gynecological. Dastjerdi, V., et al., Trans., Nurdanesh Publications, Tehran.

[3] Aghazadeh Naieni, A. (1995) What Women Need to Know. Ansariyan Press, Qom.

[4] Ebrahim, K., Ramazanpour, M. and Rezaei Sahraie, A. (2010). The Effect of Eight Weeks of Aerobic and Increasing the Hormones Estrogen and Some Factors Affecting on Bone Mass in Postmenopausal Women Disabled. Iranian Journal of Endocrinology and Metabolism, 12, 401-408.

[5] Jokhio, A.H., Rizvi, R.M., Rizvi, J. and Macarthur, C. (2013) Urinary Incontinence in Women in Rural Pakistan: Prevalence, Severity, Associated Factors and Impact on Life. BJOG: An International Journal of Obstetrics and Gynaecology, 120, 180186. https://doi.org/10.1111/1471-0528.12074

[6] Kian, Z. (2009) Effect of Pelvic Floor Muscle Exercise on Quality of Life of Women with Stress Urinary Incontinence in the Postpartum Period. MSC Thesis, Tehran University of Medical Sciences, Tehran. (In Persian)

[7] Lamiian, M., SHagerd Hadad, M., Goshtasebi, A. and Massoomi, R. (2010) Comparison of Surgical and Medical Therapy on Quality of Life in Women with Urinary Incontinence. Payesh, 10, 525-532.( In Persian) 
[8] Tashakori, M., Moghimi, A., Pilevariyan, A. and moghimiyan, M. (2006) Study of Severity and Prevalence of Stress Incontinent in Menopausal Working Women in Khorasan. Iranian Gynecol Midwifer Infertilit J, 9, 47-52. (In Persian)

[9] Nojomi, M., Baharvand, P. and Kashanian, M. (2009) Validation of Incontinence Quality of Life Questionnaire (I-QOL) in Incontinent Women. RJMS, 16, 153-161. (In Persian)

[10] Mladenović Segedi, L., Segedi, D. and Parezanović Ilić, K. (2011) Quality of Life in Woman with Urinary Incontinence. Medicinski Glasnik (Zenica), 8, 237-242.

[11] Warren-Findlow, J. and Prohaska, T.R. (2008) Families, Social Support and Self Care among Older African-American Women with Chronic Illness. American Journal of Health Promotion, 22, 342-349.

[12] Heidari, M., Alhani, F., Kazemnejad, A. and Moezzi, F. (2007) The Effect of Empowerment Model on Quality of Life of Diabetic Adolescents. Iranian Journal of Pediatrics, 17, 87-94. (In Persian)

[13] Stanhop, M. and Lancaster, J. (2008) Community \& Public Health Nursing. 7th Edition, Mosby, Maryland Heights.

[14] Broome, B.A. (2003) The Impact of Urinary Incontinence on Self-Efficacy and Quality of Life. Health and Quality of Life Outcomes, 1, 35. https://doi.org/10.1186/1477-7525-1-35

[15] Suckling, J., Lethaby, A. and Kennedy, R. (2006) Local Oestrogen for Vaginal Atrophy in Postmenopausal Women. Cochrane Database of Systematic Reviews, 4, CD001500.

[16] Schmidt, J.W., Wollner, D., Curcio, J., Riedlinger, J. and Kim, L.S. (2006) Hormone Replacement Therapy in Menopausal Women: Past Problems and Future Possibilities. Gynecological Endocrinology, 22, 564-577. https://doi.org/10.1080/09513590600927017

[17] Kim, D.K. and Chancellor, M.B. (2006) Is Estrogen for Urinary Incontinence Good or Bad? Reviews in Urology, 8, 91-92.

[18] Edwall, L., Carlström, K. and Fianu, J.A. (2008) Markers of Collagen Synthesis and Degradation in Urogenital Tissue and Serum from Women with and without Uterovaginal Prolapse. Molecular Human Reproduction, 14, 193-197. https://doi.org/10.1093/molehr/gan006

[19] Mattox, J.H. (1998) Core Text Book of Obstetrics \& Gynecology. 2nd Edition, Mosby, St. Louis.

[20] Scott, J.R., Gibbs, R.S. and Karlan, B.Y. (2003) Danforth's Obstetrics \& Gynecology. 8th Edition, Lippincott Williams \& Wilkins, Philadelphia.

[21] Satherland, C. (2001) Women's Health: A Handbook for Nurse. 2nd Edition, Churchill Living Stone, Edinburg.

[22] Quinn, Y.E., Marcia, S. and Zamania, D. (2003) Women's Health: A Primary Care Clinical Guide. 3rd Edition, Prentice Hall International, London.

[23] Skaaby, T., Husemoen, L.L., Pisinger, C., Jorgensen, T., Thuesen, B.H., Fenger, M. and Linneberg, A. (2012) Vitamin D Status and Cause-Specific Mortality: A General Population Study. PLoS One, 7, 42-52. https://doi.org/10.1371/journal.pone.0052423

[24] Berek, J.S., Rinehart, R.D., Adams, H.P.J. and Adashi, E.Y. (2002) Novak's Gynecology. 13th Edition, Lippincott Williams \& Wilkins, Philadelphia.

[25] Abu-Mouch, S., Fireman, Z., Jarchovsky, J., Zeina, A.R. and Assy, N. (2011) Vitamin D Supplementation Improves Sustained Virologic Response In Chronic Hepatitis C (Genotype 1)-Naive Patients. World Journal of Gastroenterology, 17, 5184 - 
5190. https://doi.org/10.3748/wjg.v17.i47.5184

[26] Sakala, E.P. (2005) High-Yield Obstetrics and Gynecology. 2nd Edition, Lippincott Williams \& Wilkins, New York.

[27] Smeltzer, S.C. and Bare, B.G. (2000) Brunner \& Suddarth's Text Book of Medical-Surgical Nursing. 9th Edition, Lippincott, Philadelphia.

[28] Rahman, A. and Branch, A.D. (2013) Vitamin D for Your Patients with Chronic Hepatitis C? Journal of Hepatology, 51, 184-189. https://doi.org/10.1016/j.jhep.2012.07.026

[29] Hacker, N.F., Moore, J.G. and Gambone, J.C. (2004) Essentials of Obstetrics and Gynecology. 4th Edition, Saunders, Philadelphia.

[30] Stirrat, G.M. (2000) Aids to Obstetrics and Gynecology for Mrcog. 4th Edition, Churchill Living Stone, Edinburgh.

[31] Sanfillippo, J.S. and Smith, R.P. (1998) Primary Care in Obstetric \& Gyncecology: A Handbook for Clinicians. Springer, New York.

[32] Sherburn, M., Guthrie, J.R., Dudley, E.C., O’connell, H.E. and Dennerstein, L. (2001) Is Incontinence Associated with Menopaus? Obstetrics \& Gynecology, 98, 628-633.

[33] Melmed, S., Polonsky, K., Larsen, P.R. and Kronenberg, H. (2011) Williams Textbook of Endocrinology. 13th Edition, Elsevier, Amsterdam.

[34] Bai, S.W., Jung, Y.W., Kwon, H.S., et al. (2004) The Role of Estrogen Receptor, Progenterone Receptor and p53 in Development of Stress Urinary Incontinence. Yonsei Medical Journal, 45, 885-890. https://doi.org/10.3349/ymj.2004.45.5.885

[35] Zhu, L., Lang, J., Feng, R., Chen, J. and Wong, F. (2004) Estrogen Receptor in Pelvic Floor Tissues in Patients with Stress Urinary Incontinence. International Urogynecology Journal and Pelvic Floor Dysfunction, 15, 340-343.

[36] Skala, C.E., Petry, I.B., Albrich, S., Puhl, A., Naumann, G. and Koelbl, H. (2011) The Effect of Genital and Lower Urinary Tract Symptoms on Steroid Receptor Expression in Women with Genital Prolapsed. International Urogynecology Journal, 22, 705-712. https://doi.org/10.1007/s00192-010-1327-6

[37] Connel, K.A., Guess, M.K., Chen, H.W., Lynch, T., Bercik, R. and Taylor, H.S. (2009) HOXA11 Promotes Fibroblast Proliferation and Regulates p53 in Uterosacral Ligaments. Reproductive Sciences, 16, 697-700. https://doi.org/10.1177/1933719109334260

[38] Lang, J.H., Zhu, L., Sun, Z.J. and Chen, J. (2003) Estrogen Level and Estrogen Receptors in Patient with Stress Urinary Incontinence and Pelvic Organ Prolapsed. International Journal of Gynecology \& Obstetrics, 80, 35-39.

[39] Hish, Ch., Su, T. and Change, Sh. (2008) Prevalence of and Attitude toward Urinary Incontinence in Postmenopausal Women. International Journal of Gynecology \& Obstetrics, 100, 171-174.

[40] Gulseren, L., Kalafat, D., Mandaci, H., Gulseren, S. and Comli, L. (2005) Effect of Tibolone on the Quality of Life, Anxiety-Depression Levels and Cognitive Function in Natural Menopause: An Observational Follow-Up Study. Australian and New Zealand Journal of Obstetrics and Gynaecology, 45, 71-73. https://doi.org/10.1111/j.1479-828X.2005.00345.x

[41] Longo, D., Fauci, A., Kasper, D., Hauser, S., Jamson, J. and Loscalzo, J. (2012) Harrison's Principles of Internal Medicine. Textbook Edition, McGraw-Hill Education, New York.

[42] Ashrafi, M., Kazemi-Ashtiani, S. and Eshrati, B. (2007) Menopausal Age Mean and Influence Variables on It in Tehran Persian. Kosar Medical Journal, 12, 75-82. 
[43] Speroff, L. and Fritz, M.A. (2005) Clinical Gynecology Endocrinology and Infertility. 7th Edition, Walters Kluwer Company, New York, 275-662.

[44] Green, S., Walter, P. and Kumar, V. (1986) Human Estrogen Receptor DNA Sequence, Expression and Homology. Nature, 320, 134-139. https://doi.org/10.1038/320134a0

[45] Kuiper, G.G., Enmark, E. and Pelto-Huikko, M. (1996) Cloning of a Noval Receptor Expressed in Rat Prostate and Ovary. Proceedings of the National Academy of Sciences, 93, 5925-5928. https://doi.org/10.1073/pnas.93.12.5925

[46] Keane, D. and Sullivan, S. (2000) Urinary Incontinence: Anatomy, Physiology and Pathophysiology. Obstetrics \& Gynecology, 14, 207-226.

https://doi.org/10.1053/beog.1999.0072

[47] Shelton Broom, B. (2003) The Impact of Urinary Incontinence on Self-Efficacy and Quality of Life. Internal Medicine, 1, 35.

Submit or recommend next manuscript to SCIRP and we will provide best service for you:

Accepting pre-submission inquiries through Email, Facebook, LinkedIn, Twitter, etc. A wide selection of journals (inclusive of 9 subjects, more than 200 journals)

Providing 24-hour high-quality service

User-friendly online submission system

Fair and swift peer-review system

Efficient typesetting and proofreading procedure

Display of the result of downloads and visits, as well as the number of cited articles

Maximum dissemination of your research work

Submit your manuscript at: http://papersubmission.scirp.org/

Or contact ijcm@scirp.org 